\title{
Benign Ciliary Body Neoplasm
}

National Cancer Institute

\section{Source}

National Cancer Institute. Benign Ciliary Body Neoplasm. NCI Thesaurus. Code C4779.

A non-metastasizing neoplasm that arises from the ciliary body. Representative examples include leiomyoma and adenoma of the ciliary epithelium. 